\title{
VI. Note on Kohlrausch's theory of ionic velocity
}

\section{W. C. Dampier Whetham B.A.}

To cite this article: W. C. Dampier Whetham B.A. (1891) VI. Note on Kohlrausch's theory of ionic velocity, Philosophical Magazine Series 5, 32:194, 43-44, DOI: 10.1080/14786449108621389

To link to this article: http://dx.doi.org/10.1080/14786449108621389

曲 Published online: 08 May 2009.

Submit your article to this journal

Џll Article views: 3

Q View related articles $₫$ 
molecules of the metals are similar dynamical systems, and also that

$$
\frac{n}{\mathrm{~N}}=1-\left(\frac{\theta}{\mathrm{T}}\right)^{2}
$$

This concludes the experimental inquiry as to rigidity. The result shows that rigidity in its essence is a kinetic phenomenon almost as simple in character as the elasticity of perfect gases.

[To be continued.]

VI. Note on Kohlrausch's Theory of Ionic Velocity. By W. C. Dampier Whetham, B.A., Coutts Trotter Student of 'Trinity College, Cambridge*.

T OHLRAUSCH calculates his numbers for the specific 1 velocities of different ions from measurements of the conductivities of salt-solutions, and of their migration constants, on the supposition that all the molecules of the salt present in solution are actively concerned in conveying the current. The values thus obtained were found to agree with experiment in certain cases by Prof. Oliver Lodge, and an investigation I am now engaged in carrying out seems also to confirm them. It seems to be generally supposed that this is inconsistent with any theory (such as that of dissociation) which supposes only a certain part of the salt to be active (see Lodge, B. A. Report, 1886, p. 391), though some such form of theory seems to be required by the relations shown to exist by Arrhenius, Van't Hoff', Ostwald, and others. If we examine the matter a little more closely, however, I think the two suppositions can be reconciled. Suppose that the ratio of the numbers of the active and the inactive molecules (which is generally supposed to measure the "dissociation") represents in reality the average ratio of the time during which each molecule is active to the time during which it is inactive. Every molecule is in turn active, but at any instant only a certain fraction of the molecules are active. [In terms of the dissociation hypothesis, the dissociation ratio measures the ratio of the mean free time to the mean paired time of the ions.] This is, of course, equivalent to supposing a certain fixed fraction of the whole number of molecules to be active, as far as statical effects, such as osmotic pressure, are concerned, but when we consider the velocities of the ions the case is different.

* Communicated by the Physical Society : read May 9, 1891. 
Kohlrausch calculates the relative velocity of the two ions $\mathrm{U}=u+v$ from the molecular conductivity $k / m$, where $k=$ specific conductivity of the solution, and $m$ its contents in gramme equivalents of salt, $\mathrm{U}_{1}=u+v=k / m$. If now we suppose that at any instant only $1 / n$th of the number of molecules are active, we should apparently have to put $\mathrm{U}_{2}=\frac{k n}{m}$ in order that the same current may be carried, which would give $\mathrm{U}_{2}=n \mathrm{U}_{1}$.

But this $U_{2}$ represents the actual velocity of the ions while they are "free," and if we take a "dynamical "view of the dissociation equilibrium, they are only free for $1 / n$th of their time; while combined they have no relative velocity, and so their average velocity for any long time is $\frac{1}{n} \mathrm{U}_{2}=\mathrm{U}_{1}$, the same as on Kohlrausch's hypothesis.

The investigation alluded to above, at which I am now working, seems to yield excellent results for certain cases, though it is of somewhat limited application. It consists in observing the phenomena at the junction of two salt-solutions, one of which is differently coloured to the other, when a current of electricity is passed across it. Salts are chosen which have one ion in common and the other different. Let us represent them by $\mathrm{AB}$ and $\mathrm{CB}$, and consider the junction phenomena. The effect of the molecular interchanges will be a motion of $B$ ions in one direction, and a motion of $\mathrm{C}$ ions and of $\mathrm{A}$ ions in the other. When a $C$ ion crosses the boundary,

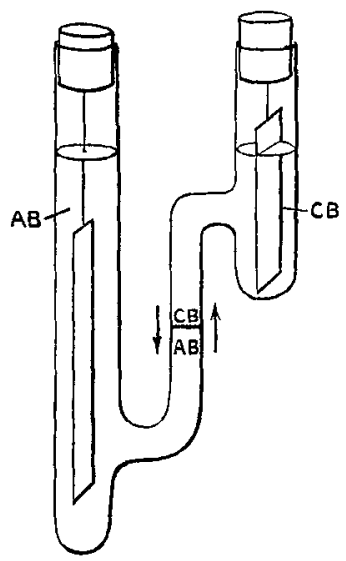
it again forms $\mathrm{CB}$, but the colour of $\mathrm{CB}$ is different to that of $\mathrm{AB}$, hence the boundary between the colours will move.

The method will be discussed when more experimental results are obtained; it appears that by measuring the rate of this motion the velocity of the ions can be arrived at. The present is merely a preliminary communication in explanation of the experiments shown to the Physical Society of I Iondon on the occasion of their recent visit to Cambridge. 